\title{
Dr. Peter Engel bleibt Präsident der Bundeszahnärztekammer
}

\author{
Die Bundesversammlung der Bundeszahnärztekammer (BZÄK) hat auf dem Deutschen Zahnärz- \\ tetag 2016 den bisherigen Geschäftsführenden Vorstand der BZÄK bestätigt. Die Delegierten \\ wählten Dr. Peter Engel zum dritten Mal in Folge zum Präsidenten. Auch die Vizepräsidenten \\ Professor Dr. Dietmar Oesterreich und Professor Dr. Christoph Benz behalten ihre Ämter.
}

Die Präsidentenwahl wurde seit Wochen mit Spannung erwartet. Denn bis zum Schluss war nicht eindeutig erkennbar, ob Engel einen Gegenkandidaten haben wird und um die Unterstützung der Delegierten kämpfen muss. Aber der Wahltag verlief dann doch sehr reibungslos. Engel erhielt mit 115 von insgesamt 151 abgegebenen Stimmen bereits im ersten Wahlgang die nötige Zwei-Drittel-Mehrheit. Die war satzungsgemäß notwenig, weil sich Engel für dieses Amt zum dritten Mal bewarb. Der Zahnarzt aus Köln ist der erste BZÄK-Präsident mit einer dritten Amtszeit.

Direkt nach der Wahl bedankte sich Engel bei den Delegierten für das Vertrauen und räumte ein, dass seine Wiederwahl für ihn keine Selbstverständlichkeit gewesen sei. „Ich werde sehr sorgfältig mit diesem Vertrauen umgehen. Und Sie können sicher sein, dass ich mit beiden Beinen auf dem Boden stehenbleibe", versprach er.

Die Wahl seines Stellvertreters Professor Dr. Dietmar Oesterreich war nicht ganz so eindeutig, aber dennoch klar. Der Präsident der Zahnärztekammer Mecklenburg-Vorpommern erhielt 92 Ja-Stimmen. Professor Dr. Christoph Benz, Vorstandsmitglied der Bayerischen Landeszahnärztekammer, wurde mit 114 Stimmen erneut im Amt bestätigt.

\section{Viel Ungemach aus Berlin und Brüssel}

BZÄK-Präsident Engel betonte während der Bundesversammlung mehrfach, dass für die Zahnärzteschaft viel Ungemach aus Berlin, aber auch aus Brüssel drohe, und appellierte an die Vertreter der Zahnärztekammern der Länder: „Engagiert Euch für den Ausbau und den Erhalt der freiberuflichen Strukturen. " Er warnte vor einer Bürgerversicherung, durch die Versicherte zu gläsernen Patienten mutierten und zahnärztliche Kompetenzen ausgehöhlt würden.

Mit Blick auf das höchst umstrittene Selbstverwaltungsstärkungsgesetz kündigte Engel an, dass sich die BZÄK massiv dafür einsetze, die Struktur der Selbstverwaltung zu erhalten. „Die Rolle der Selbstverwaltung und damit die Arbeit der Zahnärztekammern ist unantastbar", sagte er. Kammern seien die Fachaufsicht der Zahnärzte, von denen Patienten unmittelbar profitierten. Nur ein Fachmann könne die Arbeit der Kollegen einschätzen, konstatierte der Präsident.

\section{Novellierte Ausbildung - wer finanziert sie?}

Den jüngst vorgelegten Referentenentwurf für eine neue Approbationsordnung für Zahnärzte lobte Engel ausdrücklich als Erfolg. Alle Vorstellungen und Anregungen seitens der BZÄK sei- en berücksichtigt und alle Warnungen und kritischen Anmerkungen erhört worden. Allerdings habe auch dieser Entwurf einen Pferdefuß. Es sei nämlich noch nicht klar, wie die ohnehin oft klammen Universitäten eine novellierte Ausbildung finanzieren sollen: „Es kann nicht sein, dass eine neue Approbationsordnung auf hohem qualitativem Niveau vorgelegt wird, aber keine entsprechenden Gelder zur Verfügung gestellt werden“, kritisierte Engel und forderte die Bundesregierung auf, hierfür Antworten zu finden.

\section{Wahlprogramm „Gesundheitspolitische Ziele 2017-2021“}

Im nächsten Herbst sind Bundestagswahlen. Diesen Termin hat auch die BZÄK vor Augen und steigt Engels Angaben zufolge in den Wahlkampf mit ein. In den nächsten Wochen soll ein Wahlprogramm „Gesundheitspolitische Ziele 2017-2021“ entstehen, in denen wichtige Forderungen der BZÄK zu Gunsten der Patienten, der Gesellschaft und der Zahnärzte formuliert werden.

Nähere Infos zur BZÄK-Bundesversammlung gibt es unter www.bzaek.de. Melanie Fügner

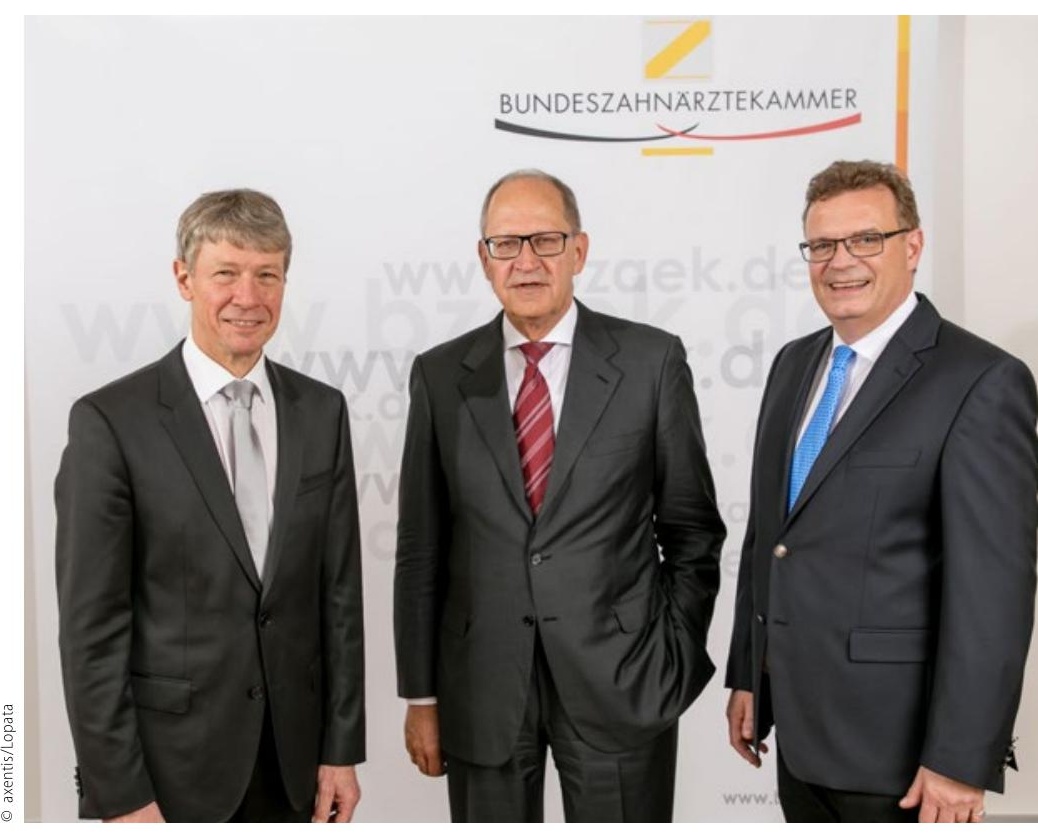

Der alte Vorstand ist der neue: Präsident Dr. Peter Engel (mi.) und seine Stellvertreter Dr. Dietmar Oesterreich und Dr. Christoph Benz 